\title{
Iron status in rats fed on diets containing marginal amounts of vitamin A
}

\author{
BY K. W. SIJTSMA ${ }^{1,2}$, G. J. VAN DEN BERG ${ }^{3}$, A. G. LEMMENS ${ }^{1}$, \\ C. E. WEST ${ }^{2}$ AND A. C. BEYNEN ${ }^{1,2 *}$ \\ ${ }^{1}$ Department of Laboratory Animal Science, State University, PO Box 80.166, 3508 TD Utrecht \\ ${ }^{2}$ Department of Human Nutrition, Agricultural University, PO Box 8129,6700 EV Wageningen \\ ${ }^{3}$ Interfaculty Reactor Institute, University of Technology, Mekelweg 15, $2629 \mathrm{JB}$ Delft,
}

The Netherlands

(Received 15 October 1992 - Accepted 5 February 1993)

\begin{abstract}
Severe vitamin A deficiency in rats is known to cause anaemia associated with growth retardation and impaired water retention. However, study of the effect of marginal vitamin $A$ intake is of more interest because such intake may mirror the situation in humans in many developing countries. Therefore, in two experiments, the effect of marginal vitamin A deficiency on $\mathrm{Fe}$ status was investigated in male rats. After $28 \mathrm{~d}$ of feeding either low- or high-vitamin A diets ( 0 or $120 v .1200$ retinol equivalents $/ \mathrm{kg}$ feed $)$, body weight and feed intake were not influenced by the level of vitamin $A$ in the diet. Liver weight was lowered by vitamin A deficiency. Water intake was not influenced in rats fed on a low-vitamin A diet. Plasma retinol concentrations were decreased in rats fed on diets low in vitamin A. Marginal vitamin A deficiency produced slightly lower blood haemoglobin concentrations; it did not systematically affect packed cell volume. The concentration of $\mathrm{Fe}$ in liver was significantly higher when diets low in vitamin $\mathrm{A}$ were fed, but hepatic Fe mass was not affected. Significantly lower Fe levels were observed in femurs of rats with vitamin $\mathrm{A}$ deficiency. The effects on liver and femur $\mathrm{Fe}$ concentrations were seen with diets adequate in $\mathrm{Fe}$ but not with diets deficient in Fe. The efficiency of apparent $\mathrm{Fe}$ absorption was significantly increased by low intakes of vitamin A, provided that the dietary Fe concentration was adequate. It is speculated that depressed uptake of $\mathrm{Fe}$ by bone marrow is the primary feature of altered Fe status in rats with marginal vitamin A deficiency.
\end{abstract}

Vitamin A: Iron: Anaemia: Rat

In women and children a direct correlation between plasma levels of vitamin $\mathrm{A}$ and blood levels of haemoglobin has been found (Hodges et al. 1978; Mejia et al. 1982; Bloem et al. 1989). This relationship is probably causal as experimentally induced vitamin A deficiency in humans produces anaemia (Wagner, 1940; Hodges et al. 1978). Intervention studies have also shown that supplementation of deficient children with vitamin A improves Fe status and increases haematopoiesis (Mohanram et al. 1977; Mejia \& Arroyave, 1982; Bloem et al. 1990). Thus, vitamin A would appear to be essential for normal haematopoiesis, but its metabolic role has not been elucidated.

Vitamin A deficiency in rats causes anaemia associated with increased Fe concentrations in liver and spleen (Mejia et al. 1979a, b; Staab et al. 1984), suggesting interference with mobilization of Fe from tissue stores. Alternatively, vitamin A deficiency could inhibit $\mathrm{Fe}$ uptake and/or haematopoiesis by bone marrow. The depressed Fe utilization may in turn cause accumulation of Fe in storage organs. Indeed, the uptake of intravenously injected radiolabelled $\mathrm{Fe}$ by the liver and spleen was significantly increased in rats with vitamin $\mathrm{A}$ deficiency, whereas that by the femur was decreased (Mejia et al. 1979 b). This implies that

* For reprints. 
vitamin A deficiency produces decreased Fe concentrations in the femur. It could also be hypothesized that altered tissue Fe distribution as induced by vitamin A deficiency triggers changes in $\mathrm{Fe}$ absorption. In rats fed on diets deficient in $\mathrm{Fe}$ and, thus, displaying reduced Fe status, the efficiency of Fe absorption is increased (Morris, 1987).

It is questionable whether the reported studies on anaemia and $\mathrm{Fe}$ status in rats with vitamin A deficiency (Mejia et al. 1979a, b; Staab et al. 1984) have used a model suitable for elucidating the mechanisms involved in the anaemias in humans in developing countries where marginal vitamin $\mathrm{A}$ intake is a problem. In these rat studies vitamin A stores were almost completely depleted. There were clinical signs of severe vitamin A deficiency such as growth retardation and fluid loss leading to haemoconcentration, which may have even masked the degree of anaemia (Koessler et al. 1926; Amine et al. 1970; Corey \& Hayes, 1972). Retarded growth can induce effects not specifically related to decreased vitamin A intake.

In the present study the major questions addressed were as follows: first, are liver Fe concentrations increased in male rats fed on diets containing marginal amounts of vitamin A? second, does marginal vitamin A deficiency influence Fe concentrations in the femur? third, does marginal vitamin A deficiency influence the efficiency of intestinal absorption of $\mathrm{Fe}$ ?

\section{MATERIALS AND METHODS}

Two experiments were carried out; control and experimental diets were identical, apart from the amounts of vitamin $\mathrm{A}$ and/or Fe. The control diet (Table 1) contained 1200 retinol equivalents and $50 \mathrm{mg} \mathrm{Fe} / \mathrm{kg}$ feed, which are the approximate requirements of young rats for these nutrients (National Research Council, 1978). In the first experiment the test diet contained no added vitamin A. In the second experiment the effect of decreased dietary vitamin A concentration (120 retinol equivalents $/ \mathrm{kg}$ feed) was studied with dietary Fe concentrations that were either adequate or marginal $(17 \mathrm{mg} / \mathrm{kg}$ feed).

\section{Animals and housing}

Male outbred Wistar rats ( $\mathrm{Cpb}: \mathrm{WU})$, about $21 \mathrm{~d}$ old, were used. The rats were purchased from a commercial breeder (Harlan CPB, Zeist, The Netherlands). They had been fed ad lib. on a commercial pelleted diet (RMH-B ${ }^{\mathbb{B}}$, Hope Farms, Woerden, The Netherlands) and tap water. The rats were kept in a room maintained at a constant temperature $\left(20-22^{\circ}\right)$ and relative humidity $(40-60 \%)$, with light from 07.00 to 19.00 hours.

In the two experiments all rats were subjected to a pre-experimental period of $10 \mathrm{~d}$ during which the purified control diet given in Table 1 was supplied ad lib. The rats had free access to demineralized water. The rats were housed in groups of three or four animals in wiretopped polycarbonate cages $(375 \times 225 \times 150 \mathrm{~mm})$ with a layer of sawdust as bedding. After the pre-experimental period (day 0 of the experiment) the rats were transferred to individual metabolism cages $\left(31400 \mathrm{~mm}^{2} \times 120 \mathrm{~mm}\right)$.

\section{Experimental design}

On day 0 the rats were divided into two (Expt 1) or four (Expt 2) dietary groups of equal size so that within each experiment the group body weight distributions were similar. One group in each experiment remained on the control diet and the others received a diet containing less vitamin A (Expt 1) and/or less Fe (Expt 2). The rats were fed on powdered, purified diets which were stored at $4^{\circ}$ until feeding, and provided with demineralized water ad lib. Separate batches of diets were made for each experiment.

The diets during the experimental period were as follows: in Expt 1 twelve rats were fed on either the control diet (Table 1) or the same diet without added vitamin A; in Expt 2 
Table 1. Composition of the control diet $(\mathrm{g} / \mathrm{kg})$

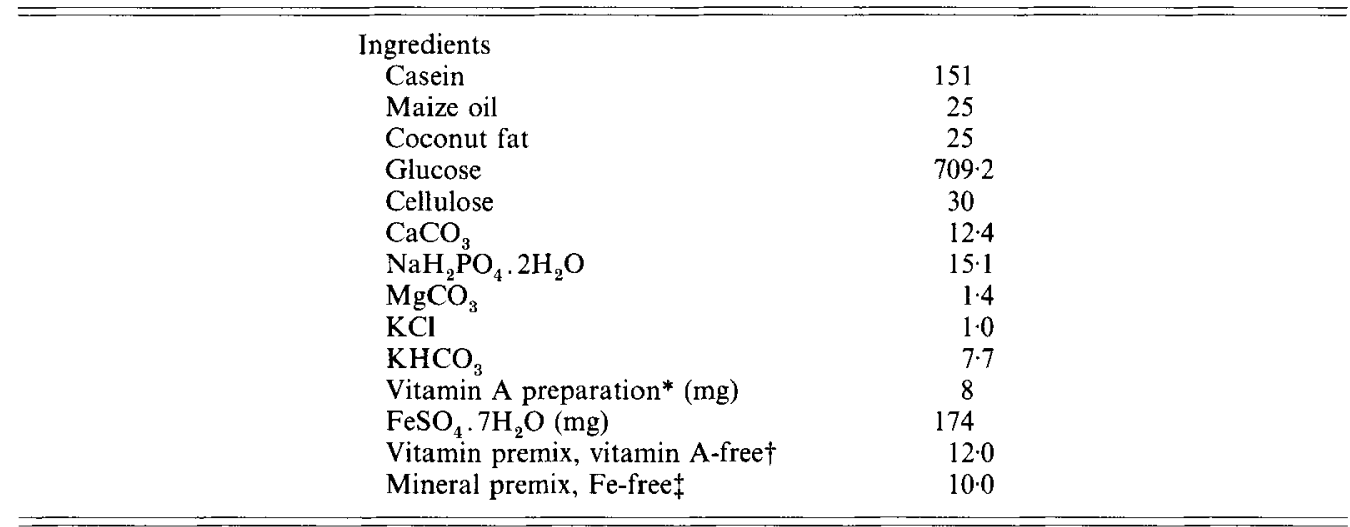

* Rovimix A $500^{\text {n }}, 156.6 \mathrm{mg} / \mathrm{g}$ (F. Hoffmann-La Roche \& Co. Ltd, Basle, Switzerland), consisting of retinyl acetate and retinyl palmitate; of this preparation 1200 retinol equivalents $/ \mathrm{kg}$ feed was added.

$\uparrow$ The vitamin A-free premix consisted of $(\mathrm{mg})$ : thiamin 4, riboflavin 3, nicotinic acid 20, DL-calcium pantothenate 17.8 , pyridoxine 6 , cyanocobalamin 50 , choline chloride 2000 , pteroylmonoglutamic acid 1 , biotin 2 , menadione $0 \cdot 05$, DL- $\alpha$ tocopheryl acetate 60 , cholecalciferol 0.025 , maize meal $9836 \cdot 125$.

$\ddagger$ The mineral premix consisted of $(\mathrm{mg}): \mathrm{MnO}_{2} 79, \mathrm{ZnSO}_{4} \cdot \mathrm{H}_{2} \mathrm{O} 33, \mathrm{NiSO}_{4} \cdot 6 \mathrm{H}_{2} \mathrm{O} 13, \mathrm{NaF} 2$, KI $0 \cdot 2$, $\mathrm{CuSO}_{4} \cdot 5 \mathrm{H}_{2} \mathrm{O} 15 \cdot 7, \mathrm{Na}_{2} \mathrm{SeO}_{3} \cdot 5 \mathrm{H}_{2} \mathrm{O} 0 \cdot 3, \mathrm{CrCl}_{3} \cdot 6 \mathrm{H}_{2} \mathrm{O} 1 \cdot 5, \mathrm{SnCl}_{2} \cdot 2 \mathrm{H}_{2} \mathrm{O} 1 \cdot 9, \mathrm{NH}_{4} \mathrm{VO}_{3} 0 \cdot 2$; maize meal $9853 \cdot 2$.

there were four dietary groups consisting of twelve rats each. One group received the control diet and another group was fed on the same diet with added $\mathrm{FeSO}_{4} .7 \mathrm{H}_{2} \mathrm{O}$ reduced to $17.4 \mathrm{mg} / \mathrm{kg}$. Two further groups were fed on the control diet with vitamin A decreased to 120 retinol equivalents $/ \mathrm{kg}$ feed and containing either 174 or $17.4 \mathrm{mg} \mathrm{FeSO}{ }_{4} .7 \mathrm{H}_{2} \mathrm{O} / \mathrm{kg}$. Chemical analysis (see below) showed that the high-vitamin $\mathrm{A}$ diets with high and low amounts of $\mathrm{FeSO}_{4}, 7 \mathrm{H}_{2} \mathrm{O}$ contained 50 and $17 \mathrm{mg} \mathrm{Fe} / \mathrm{kg}$ respectively. The low-vitamin $\mathrm{A}$ diets were found to contain 51 and $16 \mathrm{mg} \mathrm{Fe} / \mathrm{kg}$.

During the experimental periods, lasting $28 \mathrm{~d}$, feed intake and body weights were recorded. In Expt 2 water intake was also determined. During days 26-28 of Expt 2 urine and faeces of each rat were collected quantitatively. At the end of each experiment the animals were anaesthetized with diethyl ether and blood was taken by orbital puncture. The anaesthetized rats were killed by cervical dislocation. Organs were removed and frozen at $-20^{\circ}$ until analysed.

\section{Chemical analyses}

Haemoglobin concentrations in heparinized blood were determined spectrophotometrically using a test kit (Roche, Mijdrecht, The Netherlands). Packed cell volume was measured by microcentrifugation ( $5 \mathrm{~min}$ at $5000 \mathrm{~g}$ ). Plasma Fe concentrations, total Fe-binding capacity and urinary $\mathrm{Fe}$ were determined spectrophotometrically using a kit (Roche). Retinol in plasma was determined by a reversed-phase HPLC method modified from that of Driskell et al. (1982), using retinyl acetate as an internal standard. Fe in liver, spleen, femur, faeces, and feed was estimated after wet ashing with $\mathrm{HNO}_{3}$ by flame atomic absorption spectrometry (Kreeftenberg et al. 1985).

\section{Statistical analysis}

Differences between the groups fed on the diets containing high and low amounts of vitamin A were evaluated statistically with two-sided Student's $t$ test, and $P$ values are given. Data from Expt 2 were subjected to two-way analysis of variance. The probability 
Table 2. Expt 1. Effect of dietary vitamin $A$ on growth performance, plasma retinol concentrations and iron status*

(Values are means for twelve animals per dietary group)

\begin{tabular}{|c|c|c|c|c|}
\hline $\begin{array}{l}\text { Dietary vitamin A } \\
\text { concentration } \\
\text { (retinol equivalents } / \mathrm{kg} \text { )... }\end{array}$ & 1200 & 0 & $\begin{array}{c}\text { Statistical } \\
\text { significance } \\
\text { of difference: } \\
P\end{array}$ & $\begin{array}{c}\text { Pooled } \\
\text { SE }\end{array}$ \\
\hline \multicolumn{5}{|l|}{ Body wt (g) } \\
\hline Initial (day 0) & 96 & 96 & $0 \cdot 921$ & $2 \cdot 1$ \\
\hline Final (day 28) & 245 & 229 & 0.032 & $4 \cdot 9$ \\
\hline Liver wt $(\mathrm{g})$ & $8 \cdot 9$ & $7 \cdot 9$ & 0.018 & 0.28 \\
\hline Feed intake $(\mathrm{g} / \mathrm{d})$ & $16 \cdot 7$ & 160 & 0.236 & $0 \cdot 38$ \\
\hline Plasma retinol $(\mu \mathrm{mol} / \mathrm{l})$ & 1.60 & 1.45 & 0.022 & $0 \cdot 045$ \\
\hline Blood haemoglobin (mmol/l) & 8.5 & $8 \cdot 2$ & 0.076 & 0.09 \\
\hline Packed cell volume & $0 \cdot 44$ & 0.44 & $0-830$ & $0 \cdot 002$ \\
\hline \multicolumn{5}{|l|}{$\mathrm{Fe}$} \\
\hline Plasma $(\mu \mathrm{mol} / \mathrm{l})$ & $32 \cdot 6$ & $33 \cdot 2$ & $0 \cdot 798$ & 1.42 \\
\hline Liver $(\mu \mathrm{mol} / \mathrm{g}) \dagger$ & $2 \cdot 1$ & $2 \cdot 3$ & $0 \cdot 000$ & 0.04 \\
\hline Liver ( $\mu$ mol/organ) & $18 \cdot 4$ & $18 \cdot 4$ & 0.940 & 0.58 \\
\hline Spleen $(\mu \mathrm{mol} / \mathrm{g}) \dagger$ & $4 \cdot 0$ & $4 \cdot 4$ & $0 \cdot 172$ & $0 \cdot 18$ \\
\hline Femur $(\mu \mathrm{mol} / \mathrm{g}) \dagger$ & $1 \cdot 02$ & 0.92 & 0.025 & 0.029 \\
\hline
\end{tabular}

* For details of dietary treatments, see Table 1 and p. 778.

$\dagger$ On wet weight basis.

of a type I error $<0.05$ was taken as the criterion of significance. Pearson correlation coefficients were calculated for anticipated relationships between selected variables.

\section{RESULTS \\ Growth}

Feed intakes of rats fed on either the high- or low-vitamin A diets did not differ significantly (Tables 2 and 3). In Expt 1 final body weights were slightly but significantly lower in the rats fed on the diet without added vitamin A (Table 2). In Expt 2 final body weight was not significantly influenced by the decreased intake of vitamin A (Table 3). Liver wet weight was systematically reduced by low vitamin A intake. Water intakes in Expt 2 did not differ between the dietary groups (Table 3). The dietary Fe concentrations of 17 and $50 \mathrm{mg} / \mathrm{kg}$ feed did not have a different effect on either body weight or feed intake.

\section{Plasma retinol concentrations}

Plasma retinol concentrations were significantly lower in animals fed on a low-vitamin A diet compared with those fed on an adequate amount of vitamin A (Tables 2 and 3).

\section{Blood variables of Fe metabolism}

In rats fed on a diet without added vitamin A (Table 2) blood haemoglobin concentrations tended to be decreased. This was also seen in Expt 2 in rats fed on the Fe-adequate diet with low vitamin A concentration (Table 3). Control rats in Expt 1 had lower blood haemoglobin concentrations than those in Expt 2; the reason for this discrepancy is not known. Packed cell volume values were decreased significantly after feeding the lowvitamin $\mathrm{A}$ diets in Expt 2, but only if the diet was adequate in Fe (Table 3). In Expt 1 


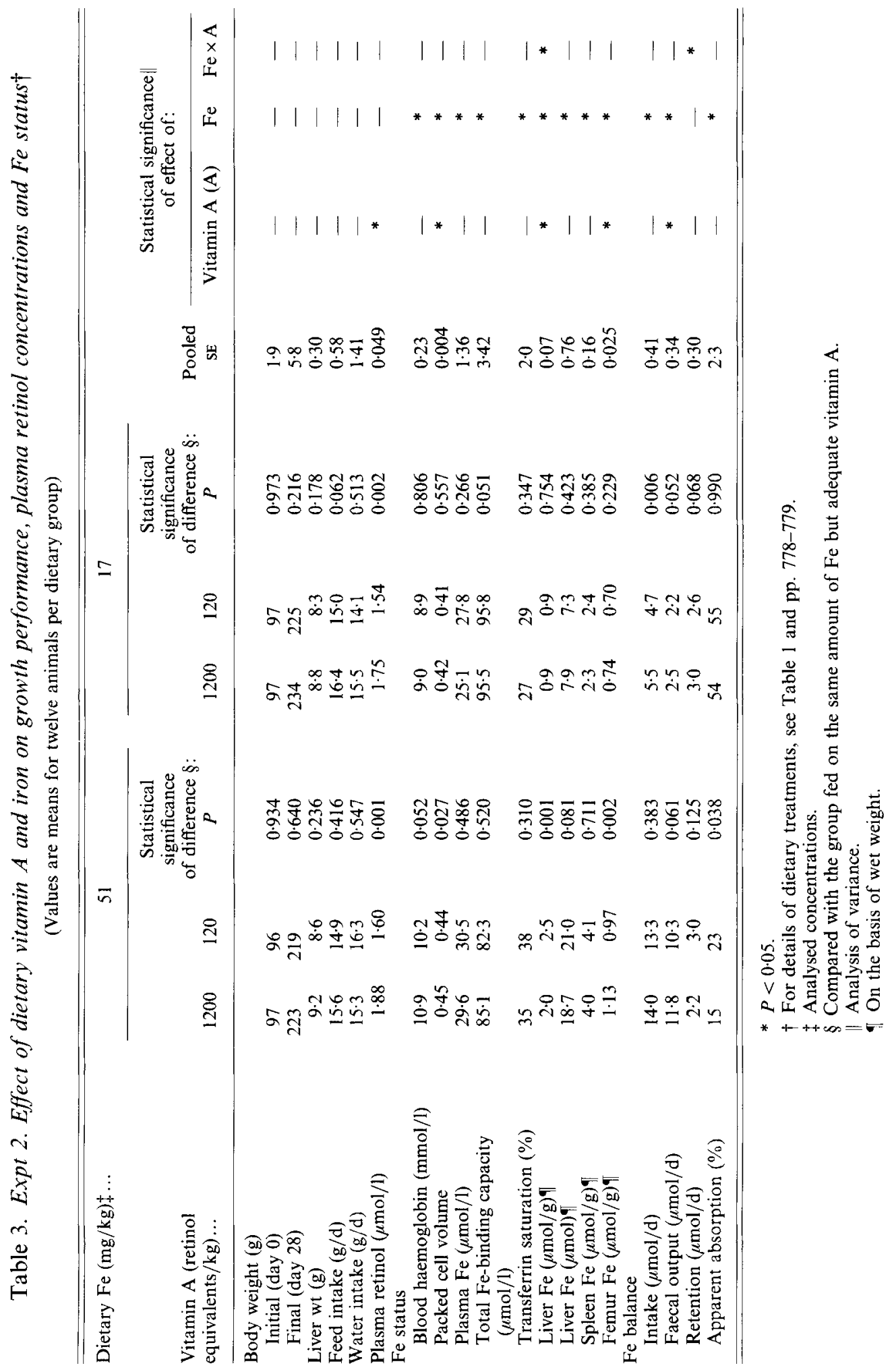




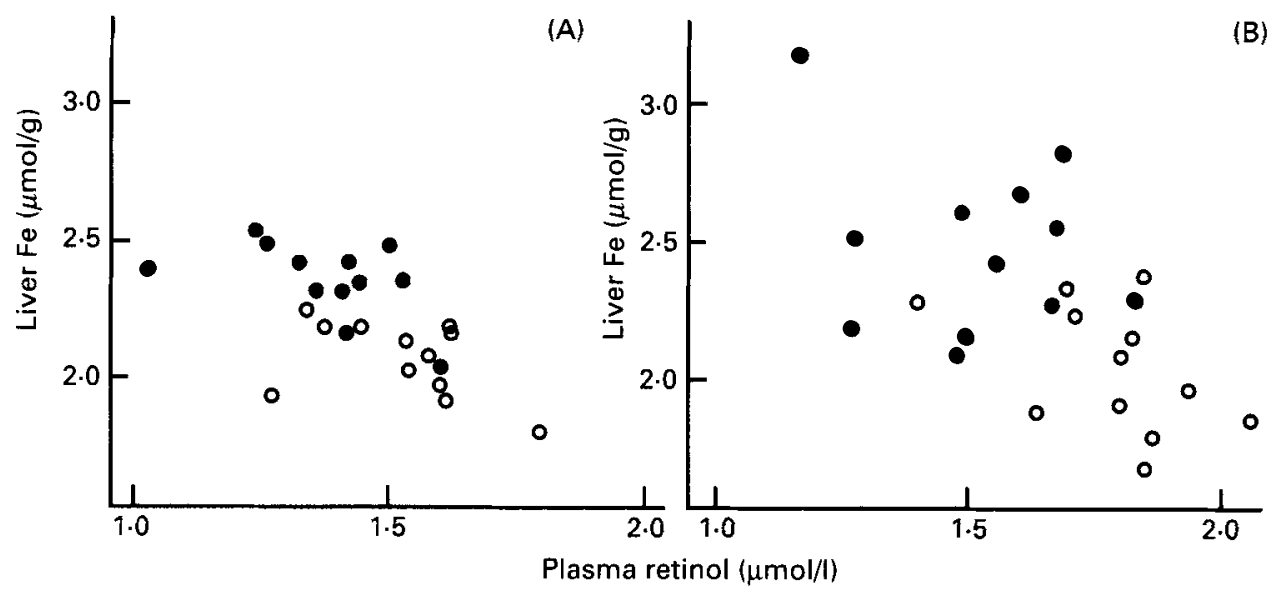

Fig. 1. Relationship between plasma retinol concentrations and liver iron concentrations in individual male rats fed on diets adequate in Fe but containing different amounts of vitamin A. (O), rats fed on an adequate amount of vitamin A ; (O), rats fed on marginal amounts of vitamin A. (A), Expt 1:r-0.63, $n 24, P<0.001 ;(\mathrm{B})$, Expt 2: $r-0.60, n 24, P<0.001$. For details of dietary treatments, see Table 1 and p. $778-779$.

packed cell volume was not affected by vitamin A intake (Table 2). Plasma Fe concentrations, total Fe-binding capacity, and saturation of plasma transferrin were not influenced significantly by vitamin A intake. In Expt 2 the effect of low intakes of iron was to decrease values for blood haemoglobin concentrations, packed cell volume, plasma $\mathrm{Fe}$ and percentage saturation of transferrin, whereas total Fe-binding capacity was increased (Table 3).

\section{Iron content of organs}

Liver Fe concentration was significantly increased after feeding the low-vitamin A diets, provided that the dietary Fe concentrations were adequate (Tables 2 and 3). Hepatic Fe mass was not influenced by the amount of vitamin A in the diet. Fig. 1 shows that in individual rats with varying plasma retinol concentrations there was a negative relationship between plasma retinol and liver Fe concentration.

In rats fed on diets containing marginal amounts of $\mathrm{Fe}$, liver $\mathrm{Fe}$ concentrations were reduced by more than $50 \%$ (Table 3 ). In Fe-deficient rats dietary vitamin A concentration did not influence liver Fe concentrations (Table 3).

Spleen $\mathrm{Fe}$ concentrations were not affected by vitamin $\mathrm{A}$ intake. The Fe contents of femurs were significantly decreased in rats fed on the low-vitamin A diets containing an adequate Fe concentration (Tables 2 and 3). Decreased intake of Fe lowered femur $\mathrm{Fe}$ concentrations; low intake of vitamin A did not further lower femur Fe (Table 3).

\section{Iron balance}

Urine did not contain detectable amounts of $\mathrm{Fe}$ so that $\mathrm{Fe}$ balance was determined by $\mathrm{Fe}$ intake and faecal excretion only. In the rats fed on a diet adequate in $\mathrm{Fe}$ a decreased intake of vitamin A produced a significant $(P<0.05)$ increase in the efficiency of apparent $\mathrm{Fe}$ absorption and tended to increase Fe retention (Table 3 ). For individual animals fed on the Fe-adequate diets but with varying amounts of vitamin $A$ there was a negative correlation between plasma retinol concentrations and apparent Fe absorption $(r-0 \cdot 45, n 24, P=$ 0.013 ). Decreasing the intake of Fe caused an increase in the efficiency of Fe absorption associated with unchanged Fe retention. Vitamin $\mathrm{A}$ intake did not influence Fe balance in rats fed on the low-Fe diet. 


\section{DISCUSSION}

The low-vitamin A diets which were fed for $28 \mathrm{~d}$ did not produce changes in body weight and feed intake while plasma retinol concentrations were only slightly decreased. On the basis of the reported relationship between plasma and liver retinol concentrations in rats (Wright \& Hall, 1979) it can be estimated that liver retinol stores may have been reduced by about $80 \%$ in the rats fed on the low-vitamin A diets. However, caution is warranted when making such an inter-study comparison because experimental conditions may have varied. Nevertheless, we feel that the rats used in the present study can be considered marginally deficient in vitamin A. In contrast, other studies (Mejia et al. 1979 a, $b$; Staab et al. 1984) on hypovitaminosis $\mathrm{A}$ and $\mathrm{Fe}$ status have used rats with severe vitamin $\mathrm{A}$ deficiency as evidenced by completely depleted stores of retinol in liver and growth retardation.

Despite the fact that our rats were only marginally deficient in vitamin $\mathrm{A}$, changes in $\mathrm{Fe}$ metabolism could be detected. Marginal vitamin A deficiency slightly lowered group mean blood haemoglobin concentrations. In studies using rats with severe vitamin A deficiency increased haemoglobin concentrations and packed cell volume values have been found (Koessler et al. 1926; McLaren et al. 1965; Amine et al. 1970; Corey \& Hayes, 1972). This can be explained by haemoconcentration as severe vitamin A deficiency induces impaired water retention (Mahant \& Eaton, 1976). It is unlikely that the observed tendency towards decreased haemoglobin concentrations as induced by marginal vitamin A deficiency was biased by haemoconcentration. In Expt 2 water intake and urinary excretion were measured, and no effect of dietary vitamin A concentration was found. Furthermore, haemoconcentration only appears to occur when there is retardation of growth (Koessler et al. 1926; Corey \& Hayes, 1972).

Although marginal vitamin A deficiency slightly lowered blood haemoglobin concentrations it did not influence plasma Fe concentrations, total Fe-binding capacity and transferrin saturation. Marginal Fe intake, on the other hand, lowered plasma $\mathrm{Fe}$ concentrations and saturation of transferrin and total Fe-binding capacity. This suggests that the mechanisms underlying the anaemias produced by deficiencies of $\mathrm{Fe}$ and vitamin $A$ are different. This agrees with the observation that severe vitamin A deficiency causes hypochromic microcytic polycythaemia, whereas $\mathrm{Fe}$ deficiency results in hypochromic microcytic anaemia (Amine et al. 1970).

Further observations also indicate that vitamin $\mathrm{A}$ and $\mathrm{Fe}$ deficiencies have different effects on Fe metabolism. As observed in studies using rats with severe vitamin A deficiency (Mejia et al. 1979a,b; Staab et al. 1984), marginal vitamin A deficiency was found to elevate $\mathrm{Fe}$ concentrations consistently in liver. In the rats fed on Fe-adequate diets but different amounts of vitamin A there was a negative correlation between plasma retinol concentrations and liver Fe concentrations (Fig. 1). Femur Fe concentrations were slightly, but significantly, lower when marginal amounts of vitamin $\mathrm{A}$ were fed in diets adequate in Fe. As far as we know, effects of vitamin A status on Fe concentrations in the femur have not been reported previously.

In the rats fed on a diet adequate in Fe but with marginal vitamin A the efficiency of apparent $\mathrm{Fe}$ absorption was increased. It cannot be excluded that impaired Fe status as induced by vitamin A deficiency depresses the loss of endogenous $\mathrm{Fe}$ and that, unlike apparent absorption, true absorption of Fe was not raised. In any event, the increase in apparent $\mathrm{Fe}$ absorption tended to be associated with elevated Fe retention (Table 3). The inverse relationship between vitamin $\mathrm{A}$ intake or plasma retinol concentration and the efficiency of apparent $\mathrm{Fe}$ absorption may seem to be at variance with the observation that vitamin A deficiency lowered Fe status. One interpretation of these results is that vitamin 


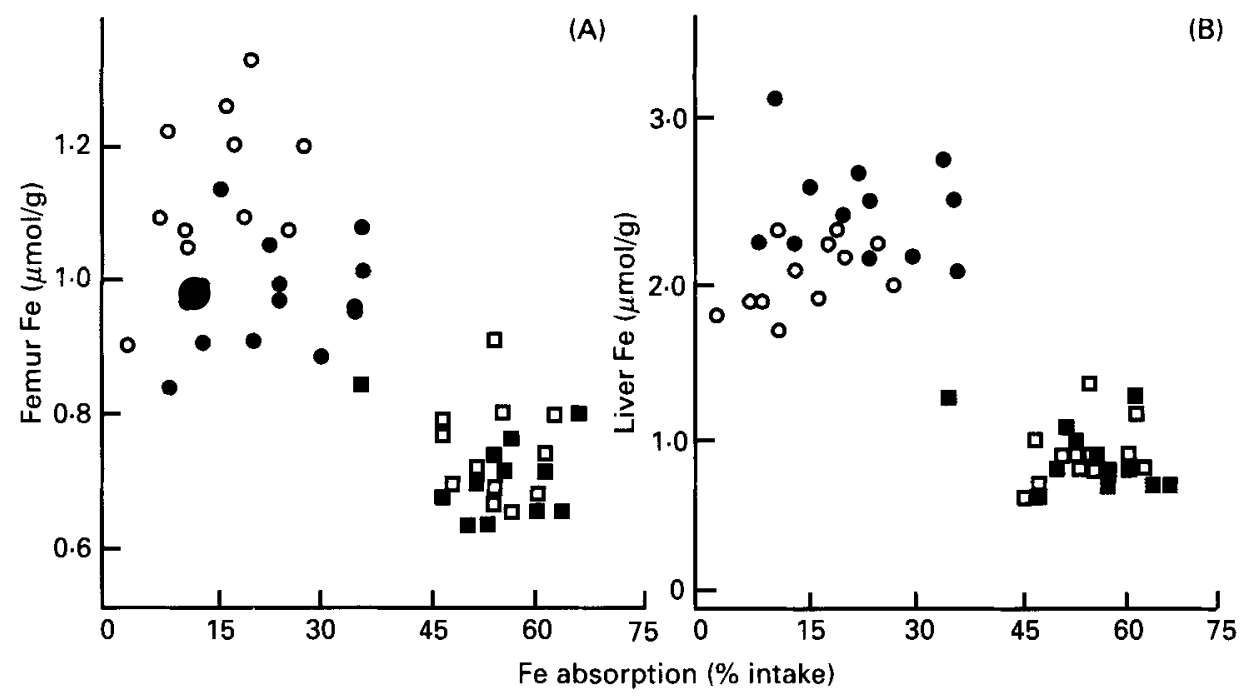

Fig. 2. Relationships between apparent iron absorption and either (A) femur Fe concentration $(r-0.78, n 48$, $P<0.001)$ or (B) hepatic Fe concentration $(r-0.81, n 48, P<0.001)$ for all individual animals of Expt 2. $(O, \square)$, Rats fed on an adequate amount of vitamin $A ;(\mathbf{O}, \mathbf{\square})$, rats fed on a marginal amount of vitamin $A ;(O, 0)$, rats fed on an adequate amount of $\mathrm{Fe} ;(\square, \mathbf{\square})$, rats fed on a marginal amount of Fe. For details of dietary treatments, see Table 1 and pp. 778-779.

A reduces $\mathrm{Fe}$ status, which in turn triggers compensatory mechanisms, such as raised $\mathrm{Fe}$ absorption, in an attempt to prevent further lowering of Fe status. Marginal Fe deficiency also increased the efficiency of Fe absorption, a phenomenon that is well known (Morris, 1987). For the individual animals in Expt 2 the efficiency of Fe absorption was inversely related with $\mathrm{Fe}$ concentrations in the femur (Fig. 2), suggesting that femur Fe status regulates $\mathrm{Fe}$ absorption. Hepatic $\mathrm{Fe}$ concentrations were also negatively associated with apparent $\mathrm{Fe}$ absorption, but the correlation was mainly caused by clustering of the $\mathrm{Fe}$ adequate and Fe-deficient groups at the extreme ends of the scale (Fig. 2). For rats given $\mathrm{Fe}$-adequate diets with either an adequate or marginal amount of vitamin $\mathrm{A}$ there was no significant relationship ( $r 0.29, n 24, P=0 \cdot 162)$. Thus, Fe concentration of femur may be more important in determining $\mathrm{Fe}$ absorption than that of liver.

Mejia et al. (1979b) determined turnover of intragastrically- or intraperitoneallyadministered ${ }^{59} \mathrm{Fe}$ in vitamin A-deficient and pair-fed control rats, and calculated that vitamin A deficiency increased the efficiency of true Fe absorption. This outcome indicates that the observed increase in apparent $\mathrm{Fe}$ absorption in rats with marginal vitamin $\mathrm{A}$ deficiency may not be biased by changes in faecal excretion of endogenous Fe. However, it should be noted that in the study of Mejia et al. $(1979 b)$ there was no difference in $\mathrm{Fe}$ absorption between ad lib.-fed controls and the vitamin A-deficient rats which showed decreased feed intakes. This suggests that feed intake also affects Fe absorption. In our study feed intake of vitamin A-adequate and marginally deficient animals was similar. Thus, the observed increase in apparent $\mathrm{Fe}$ absorption in deficient rats cannot have been affected by feed intake.

As to the metabolic basis for the tendency towards anaemia in male rats with marginal vitamin A deficiency fed on diets adequate in Fe, we can only speculate. Possibly, the primary feature is decreased uptake of plasma Fe by bone marrow. Vitamin A deficiency in rats has been reported to cause impaired uptake of intravenously injected ${ }^{58} \mathrm{Fe}$ by the femur (Mejia et al. 1979 b). This could lead to the observed decreased concentrations of Fe 
in the femur. Impaired uptake of Fe by the femur could also explain the reported inhibition of incorporation of ${ }^{59} \mathrm{Fe}$ into erythrocytes of rats with vitamin A deficiency (Mejia et al. $1979 \mathrm{~b}$ ). The decreased utilization of $\mathrm{Fe}$ by bone marrow may cause the observed accumulation of $\mathrm{Fe}$ in the liver. Possibly, the former effect triggers the uptake of Fe by liver rather than inhibiting $\mathrm{Fe}$ mobilization from this tissue. Indeed, the uptake by the liver of circulating radiolabelled $\mathrm{Fe}$ is enhanced in rats with vitamin A deficiency (Mejia et al. $1979 b$ ). Alternatively, enhanced Fe uptake by the liver could be related to the increased efficiency of apparent $\mathrm{Fe}$ absorption in rats with marginal vitamin $\mathrm{A}$ deficiency. The observation that marginal amounts of vitamin $\mathrm{A}$ in a diet deficient in Fe did not influence tissue Fe concentrations and blood haemoglobin could imply that under this condition it is the Fe rather than vitamin A provision that determines uptake of Fe by tissues.

\section{REFERENCES}

Amine, E. K., Corey, J., Hegsted, D. M. \& Hayes, K. C. (1970). Comparative hematology during deficiencies of iron and vitamin A in the rat. Journal of Nutrition 100, 1033-1040.

Bloem, M. W., Wedel, M., Egger, R. J., Andries, M., Speek, A. J., Schrijver, J., Saowakontha, S. \& Schreurs, W. H. P. (1989). Iron metabolism and vitamin A deficiency in children in North East Thailand. American Journal of Clinical Nutrition 50, 332-339.

Bloem, M. W., Wedel, M., Van Agtmaal, E. J., Speek, A. J., Saowakontha, S. \& Schreurs, W. H. P. (1990). Vitamin A intervention: short term effects of a single, oral, massive dose on iron metabolism. American Journal of Clinical Nutrition 51, 76-79.

Corey, J. C. \& Hayes, K. C. (1972). Cerebrospinal fluid pressure, growth and hematology in relation to retinol status of the rat in acute vitamin A deficiency. Journal of Nutrition 102, 1585-1594.

Driskell, W. J., Neese, J. W., Bryant, C. C. \& Bashor, M. M. (1982). Measurement of vitamin A and E in human sera by high performance liquid chromatography. Journal of Chromatography 231, 439-444.

Hodges, R. E., Sauberlich, H. E., Canham, D. L. W., Rucker, R. B., Mejia, L. A. \& Mohanram, M. (1978). Hematopoietic studies in vitamin A deficiency. American Journal of Clinical Nutrition 31, 876-885.

Koessler, K. K., Maurer, S. \& Loughin, R. (1926). The relation of anemia, primary and secondary, to vitamin A deficiency. Journal of the American Medical Association 14, 476-482.

Kreeftenberg, H. G., Koopman, B. J., Huizinga, J. R., Van Vilsteren, T., Wolters, B. G. \& Gips, C. H. (1985). Measurement of iron in liver biopsies - a comparison of three analytical methods. Clinica Chimica Acta 144, 255-262.

McLaren, D. S., Tchalian, M. \& Ajans, Z. A. (1965). Biochemical and hematological changes in the vitamin A deficient rat. American Journal of Clinical Nutrition 17, 131-138.

Mahant, L. \& Eaton, H. D. (1976). Effect of chronic hypovitaminosis on water metabolism in the weanling rat. Journal of Nutrition 106, 1817-1826.

Mejia, L. A. \& Arroyave, G. (1982). The effect of vitamin A fortification of sugar on iron metabolism in preschool children in Guatemala. American Journal of Clinical Nutrition 36, 87-93.

Mejia, L. A., Hodges, R. E., Arroyave, G., Viteri, F. \& Torun, B. (1982). Vitamin A deficiency and anemia in Central American children. American Journal of Clinical Nutrition 30, 1175-1184.

Mejia, L. A., Hodges, R. E. \& Rucker, R. B. (1979a). Clinical signs of anemia in vitamin A-deficient rats. American Journal of Clinical Nutrition 32, 1439-1444.

Mejia, L. A., Hodges, R. E. \& Rucker, R. B. (1979b). Role of vitamin A in the absorption, retention and distribution of iron in the rat. Joumal of Nutrition 109, 129-137.

Mohanram, M., Kulkarni, K. A. \& Reddy, V. (1977). Hematologic studies in vitamin A-deficient children. International Journal for Vitamin and Nutrition Research 47, 389-393.

Morris, E. R. (1987). Iron. In Trace Elements in Human and Animal Nutrition, vol. 1, pp. 79-142 [W. Mertz, editor]. San Diego, CA: Academic Press Inc.

National Research Council (1978). Nutrient requirements of domestic animals. Nutrient Requirements of Laboratory Animals no. 10,3rd ed. Washington, DC: National Academy of Sciences.

Staab, D. D., Hodges, R. E., Metcalf, W. K. \& Smith, J. L. (1984). Relationship between vitamin A and iron in the liver. Journal of Nutrition 114, $840-844$.

Wagner, K. H. (1940). Die experimentelle Avitaminose A beim Menschen (Experimenmtal hypovitaminosis A in man). Hoppe-Seyler's Zeitschrift für Physiologische Chemie 264, 153-189.

Wright, K. E. \& Hall, R. C. Jr (1979). Association between plasma and liver vitamin A levels in the calf; weanling pig, rabbit and rat; and adult goat fed fixed intakes of vitamin A. Journal of Nutrition 109, 1063-1072. 